\title{
Basic Educational Competences for the Physical Education Teachers from the Perspective of the Teachers Themselves
}

\author{
Jasser Hosny Mutlaq Alananzeh*, Ammar Abdulla Mahmoud Alfrehat**
}

\begin{abstract}
:
The study aimed at investigating the most important basic educational competences for the physical education teachers from their own perspective in light of the variables: sex, academic qualification, teaching experience, and educational stage (basic, secondary). The sample consisted of (79) teachers. The researchers designed the instrument of the study to measure the competences. The questionnaire included (40) items delivered into four domains: planning, carrying out the educational situation, managing the educational situation and assessment. The findings indicated that all domains are important for the teacher in teaching. The arrangement of the important degree for the domains was as follows: the carrying out of the educational situation, managing of the education situation, planning and the competence of assessment was in the last rank. The findings also indicated that there were no statistically significant differences in the appreciation of physical education teachers for the importance of the educational competences performance due to any of the variables of the study.
\end{abstract}

Keywords:Physical education teacher, Basic educational competences

\section{Introduction:}

A 1 the processes of development in the educational process are basically based on the teacher and on his/her educational competences that enable him/her to achieve the educational objectives for the stages/he is teaching. The teacher is the first in charge of carrying out the curriculum, choosing teaching methods and effective educational activities and using the educational technology and the suitable assessment methods (Al Subai'i 2003). The countries that try to achieve comprehensive progress in all fields of life need teachers having many competences such as effective planning , assessment, modern and effective teaching methods and successful class management ( ALghezwat, 2002). Therefore, educational authority efforts in most countries all over the world tend to educate teachers through competency based teacher education programs

\footnotetext{
* Department of Basic Science, Al-Balqa Applied University/Ajloun College, Jordan.

** Department of Educational Sciences, Al-Balqa Applied University/Ajloun College, Jordan.
}

(CB T E). Such programs and training will enable the teacher to do his / her work effectively which shows the real progress. The process of teaching could be analyzed and classified into a group of competences. If such competences are acquired by the teacher, she will be a successful and effective teacher (Mare'i, 1983).

In the light of the general objectives for educating the teachers, it is expected that the teachers could acquire a number of educational competences of performance as the teaching career forms a system consisting of main components that have functions and interact with each other. Those components are: planning in light of the philosophy of education and its objectives, the curriculum which consists of experiences, the carrying out of the curriculam and the assessment of the outcomes of the teaching (Mare'i and Balqees , 1986). According to the importance of the educational competences in educating teachers there are many definitions for it.

Jamel, (2001) defined competences as the whole behaviors and actions of the teacher that include 
knowledge, attitudes and skills during the educational situation. Al Helah (2002) defined competences as the ability of the teacher in doing a specific behavior which is related to his/her educational tasks in teaching including the knowledge, skills, attitudes and special values connected directly to teaching to achieve the demanded objectives in teaching. Where $\mathrm{Al}$ Fatlawi (2003) is defined it as the abilities that are presented by behavioral expressions including a group of tasks.

(cognitive, skilful and emotional), lead to the final performance that is expected to be accomplished at a good level which could be noticed and evaluated by different ways of observations.Al Omari (2005) Competency in teaching means the teachers capability of doing a specific cognitive/ emotional or performance action or behavior in the educational situation properly to get the desirable outcomes in less effort and less time.

The researchers defined competency as the teachers' achievement of teaching tasks in the right way by using all what they have of knowledge and skills to achieve the needed outcomes in time. Gary (1980) classified the necessary forms of competency that the teacher needs into three types:

1- Knowledge competences which identify the details of the knowledge concepts that the teacher shows to the students. Such concepts do not only include the information and facts, but also include the competences of continuous learning and using knowledge tools in the practical fields which are very important for the teacher. Such competences could be measured directly by paper and pen or indirectly through the observation checklist for the teaching performance.

2- Performance competences which indicate the teaching behaviors that are expected to be shown up by the teacher. Because the performance competences deal with the processes that take place inside the classroom, the best measurable method is the observation checklist for what is going inside the classroom or in any teaching situation.

3- Consequence competences which indicate the outcomes of the student (achievement, skills, attitudes) that are resulted from the use of a number of knowledge and performance competences the teacher has. Such competences could be content behaviors or processes that are measured by structured achievement test. As for those competences of processes, they provoke the students' feelings and attitudes that are caused by the teacher. The consequence competences related to the processes could be measured through the observation of the students inside the classroom, in the playground or in the educational situation.

Teachers are similar in their general competences in all educational stages to accomplish their work. Those competences are beneficial for teachers and supervisors. But they are much more useful for the teachers because such competences identify the extent of the teachers' proper accomplish of his/her work and help him/her in assessing his/her work on his/her own.

The benefit of such competences for the supervisors is to identify the knowledge and skills they need to train the pre-service teachers in the initial preparing stage. Those pre-service teachers need much training and knowledge to be able to do their work (Bin Ali and Murad, 2003).

\section{Problem of the study:}

Considering the process of continuous assessment for the teacher's performance is increasing because it is considered the basic step in identifying the basic features for the future school. Such assessment reveals different problems that face the educational process subjectively. In addition, it also reveals the characteristics and demands of such process to enable those in authority to judge the competence of the educational system to help in gaining accurate future perspectives and visions for subjective renewal for the educational system. Moreover, continuous assessment help in controlling the big quantitative expansion in educating teachers on the account of the good quality of teaching. Furthermore, it also helps in meeting the demands of development and in facing the future challenges. Having teaching as a career demands educational competences that should be practiced by the teachers in all 
educational stages to enable them to do their work in all its roles effectively.

Competences save the teachers' time and make the work easier and more effective. This study has to answer the following questions:

1. What are the basic necessary educational competences for the physical education teachers from their own perspective?

2. Are there any differences in the estimation of physical education teachers in the Governorate of Ajloun for the basic necessary educational competences in teaching physical education due to the variables of sex (male, female), the educational stage ( secondary, basic or secondary and basic together), the academic level (B.A. degree, higher education ), years of experience (1-5,6-10, -over 11 years ), from the teachers' perspective?

\section{Objectives of the study the study aimed at achieving the following:}

1. Identifying the most important basic education competences for the physical education teachers from their own perspective.

2. Identifying whether there were differences between the physical education teachers according to there appreciation for the important necessary educational competences in teaching according to the variables: sex, educational stage and experience years.

\section{Significance of the study:}

The importance of the study is originated from the role of the physical education teachers in forming the student's character .Therefore, this study could contribute in achieving the following:

1. Forming a list of the necessary educational competences for the physical education teachers and help them in improving their performance level in light of their available competences.

2. Providing those who are in charge of educating physical education in-service teachers in the faculty of physical education and educational sciences in the Jordanian universities with feeding back about the real practice of basic educational competences for physical education teachers to enhance the strong points and treat the weak ones in such practices.

3. Opening a way for the researchers to make more studies dealing with educating and preparing physical education teachers by considering other variables.

\section{Definition of Terms:}

Educational competences: It is the ability and the best level an individual can get by having the suitable training and education. Competences can be noticed and evaluated through all the achievements an individual has.

Performance competences: A collection of skills, knowledge and behaviors that all teachers of physical education should have to be able to do his/her job in teaching which will be measured by the instrument of this study.

Educational stage: It is the educational stage for the physical education teacher. It is divided into two main stages: the basic education from the first basic grade to the tenth grade, the secondary education from the first secondary until the second secondary grade.

\section{Limitations of the study:}

The study is limited to the sample of the study that includes the in - service physical education teacher in the directorate of education in the Governorate of Ajloun for the academic year 2010/2011. It is also limited to the instrument of the study and its items and the answers of the participants.

\section{Related Studies:}

Ja'neeni (2000) conducted a study aimed at knowing the basic competences for teachers in the secondary stage in Jordan from their own perspective the sample consisted of (240) male and female teachers. The findings indicated the relative importance for the domains arranged as follows: being committed to the morals of the career, teaching skills, class management, lesson planning, knowledge competences, assessment and communication skills. The study showed an effect for the variable of teaching secondary stage in favor of art stream in the 
knowledge competences and communication skills. The study showed statistically significant differences for the educational experience variable in all levels of competencies and for the experience variable in favor of male and female teachers of very long period experience in the knowledge and lesson planning competencies. The study indicated no effect for the variables of sex and academic level.

Another study by Shetewi (2001) indicated that the teachers' practice for the competencies in all domains was big in a mean score of $79.4 \%$.He conducted the study in the north of Palestine to investigate the practice extent for the educational competences by teachers of biology according to the variables of sex, experience place of work and academic level. The sample consisted of (170) male and female teachers.

The findings also showed statistically significant differences for the sex variable in favor of female teachers and for teaching place variable in favor of city teachers and also for the academic level variable in favor of higher educational level.

Kilber (2002) conducted a study aimed at making a list for the necessary educational competences for history in NevadaUniversity. The researcher arranged the competencies according to its importance for the teachers. The researcher put (186) competences within six domains arranged as its priority: human competence, assessment, planning, teaching, educational experience and class management.

A study by Fakhuri and Bin Ali (2002) showed the availability of educational competences for male and female teachers in a high degree except for some competences which are seldom available or not in the following domains: carrying out, assessment, academic and vocational developing. There were no statistically significant differences between the opinions of male and female supervisors according to the variables of specialization, sex, academic level and experience in the extent of the availability of competences for male and female teachers.

Abu Nemrah study (2003) showed that the physical education teachers in the basic stage have the performance competence in a high degree from their own perspective; whereas from the perspective of their principals their competence was in a medium level. The findings indicated statistically significant differences in the degree of having performance competences for the teachers in the domains of the study attributed to the variables of sex, academic level, experience and the interaction between them, from the perspective of the teachers and the principals the sample consisted of (243) male and female teachers and (62) headmasters and headmistresses chosen randomly from school in Jordan. The instrument consisted of (44) items covering three areas: planning, carrying out of lessons and assessment.

A study by Bin Ali and Murad (2003) showed statistically significant differences in the four areas related to assessment: planning , carrying out , class management and the teachers' personality in favor of the educational qualified teachers the sample consisted of (121) teachers. There were also statistically significant differences between the mean scores of assessment areas according to experience levels.

Another study by Abdel Haq (2004) showed that the basic educational competences that physical education teachers have in the first basic stage in the governorate of Naples were high in planning and medium in carrying out and assessment for all the participants. The sample consisted of (60) teachers and 60 principals The findings also showed statistically significant differences at the level of ( $\alpha 0.05)$ between the perspectives of male and female principals and the male and female teachers for the first basic stage in favor of the teachers.

A study by Al Omari (2005) showed the estimations of computer science in Jordan teachers for the importance of educational competences were high; whereas their estimations for the practice degree for such competences were medium. The findings showed statistically significant differences at the level of $(\alpha=0.05)$ on the degree of necessity for the educational competences attributed to the variable of academic level in favor of B.A. degree. There were also statistically significant differences on the degree of practicing the educational competences attributed to the educational qualification and in favor of those who have no educational qualification. The 
findings also showed a medium correlation according to Pearson Correlation among all domains of the study - except for the competences after teaching- with those competences by the teachers was strong.

Another study by Al Oleimat and Qutaish (2007) showed the degree of practicing the competences was educationally less than normal. The most domains of competences practiced was educational situation management while the least domain of competences in practice was using the computer. The sample consisted of (96) male and female teachers. The instrument consisted also of (68) items delivered into six domains: planning, lesson carrying out, using the lab, managing the education situation using the computer and assessment.

The findings showed statistically significant differences in the practice degree for the science teachers in the educational performance competences in the domains of carrying out the lesson and assessment attributed to the specialization in favor of teachers who have educational domain teacher specialization. There were also statistically significant differences in the practice of science teachers for the educational performance competence in planning and assessment due to sex in favor of females and also in computer domain in favor of males. But there were no statistically significant differences in the degree of practice for the science teachers in the competences attributed to teaching experience whether in the management as a whole or in each domain alone.
It is obvious from the related studies that most of them assured the necessity for acquiring the teacher the basic educational competences regardless the specific competences for the material they teach. In addition, most studies considered the opinions of the experienced educationalists which area very important way in providing the teacher by the necessary educational competences.

The finings of the related studies were different in the degree of practice for the participants in the related studies for the basic educational competences. This study is similar to those studies in having the same variables which the findings of the related studies showed variations and differences about it. But in this study there was a new variable which the related studies did not include, the variable of the educational stage the teachers deal with. This study benefited from the related studies in assigning the instrument and in identifying the procedures of the study.

\section{The Population and Sample of the Study:}

The population of the study included all physical education teachers in the Directorate of Education in the Governorate of Ajloun in the academic year 2010 / 2011 in the second semester. There were (79) male and female teachers. The sample was the (79) teachers who all responded to the instrument used in this study. Table (1) shows the distribution of the sample according to the variables of the study. 
Table (1)

Distribution of the Participants According to the Variables of the Study:

\begin{tabular}{|c|c|c|c|}
\hline \multirow{2}{*}{ Sex } & Mariable & Frequency & Percentage \\
\cline { 2 - 4 } & Female & $\mathbf{3 4}$ & $\mathbf{4 3 \%}$ \\
\hline \multirow{2}{*}{$\begin{array}{c}\text { Academic } \\
\text { qualification }\end{array}$} & B .A degree & $\mathbf{4 5}$ & $\mathbf{5 7 \%}$ \\
\cline { 2 - 4 } & After B.A degree & $\mathbf{6 0}$ & $\mathbf{7 6 \%}$ \\
\hline \multirow{2}{*}{$\begin{array}{c}\text { Educational } \\
\text { stage }\end{array}$} & Secondary & $\mathbf{1 9}$ & $\mathbf{2 4 \%}$ \\
\cline { 2 - 4 } & Basic & $\mathbf{2 6}$ & $\mathbf{1 3 \%}$ \\
\cline { 2 - 4 } & Secondary and Basic & $\mathbf{4 3}$ & $\mathbf{3 3 \%}$ \\
\hline \multirow{2}{*}{$\begin{array}{c}\text { Years of } \\
\text { experience }\end{array}$} & $\mathbf{1 - 5}$ years & $\mathbf{2 7}$ & $\mathbf{3 4 \%}$ \\
\cline { 2 - 4 } & $\mathbf{6 - 1 0}$ years & 16 & $20 \%$ \\
\cline { 2 - 4 } & $\mathbf{O v e r} 11$ years & $\mathbf{3 6}$ & $\mathbf{4 6 \%}$ \\
\hline
\end{tabular}

\section{The Instrument of the Study:}

For achieving the objectives and to answer the questions of the study, the researchers designed an instrument to measure the educational competences that the participants have after reviewing the literature in this domain. The researchers benefited from some measurable tools from the related literature. Abu Nemrah (2003), Abdel Haq (2004), Al Omari and Oleimat and al Qutaish (2007) and ALghezwat (2002). The measurement tool in the instrument was divided into four domains for the educational competences: planning for educational situation, carrying out the educational situations, management of the educational situation and assessment. A fifth gradual measure was used to correct the responses on the items. Each item of the responses was (applied at a very high degree, applied at a high degree, applied at a medium degree, applied at a weak degree, applied in a very weak degree). The grades were in sequence $(5,4,3,2,1)$.

\section{Validity:}

The instrument of the study was validated by being judged by (10) specialized jury in the fields of: physical education, measurement and evaluation, educational psychology, and curriculum and instruction. The researchers made the suitable modifications in light of the comments and suggestions by the jury. After the modification the instrument consisted of (40) items delivered into (10) items for each domain.

\section{Reliability:}

To verify the reliability of the instrument Corn Bach Alpha was used. Table (2) explained that.

Table (2)

Reliability of the Instrument for each Domain and for the Instrument as a Whole

\begin{tabular}{|l|c|}
\hline Mathematical ways Domains & Corn Bach Alpha \\
\hline Planning competency & $\bullet 0.84$ \\
\hline Carrying out educational situation & $\bullet 0.82$ \\
\hline Management of educational situation & $\bullet 0.77$ \\
\hline Assessment & $\bullet 0.75$ \\
\hline The instrument as a whole & $\bullet 0.86$ \\
\hline
\end{tabular}

Reference level at $(\alpha=0.05)$

It is clear that the instrument of the study is

validated and reliable which is accepted for research purposes. 
For correcting the responses for the instruments, the researchers gave grades for the estimation categories as follows:

Grade (5) for the first level (applied at a very high degree).

Grade (4) for the second level (applied at a high degree).

Grade (3) for the third level (applied at a medium degree).

Grade (2) for the fourth level (applied at a weak degree).

Grade (1) for the fifth level applied at a very weak degree.

According to this classification, the highest grade the responded teacher could gain on this measurement is: $(40 \times 5=200$ degree $)$ and the lowest grade is : $(40 \times 1=40)$.

The researchers adopted the following criteria to identity the hard pressure situations that the students face:

(High) degree if the mean score of the answer is over (3.5).
(Medium) degree if the mean score is (2.5-3.5). But (weak) degree if the mean score is less than (2.5).

\section{Statistical procedures:}

For answering the first question the mean scores and the standard deviations were done. To answer the second question the researcher used the mean scores, the standard deviations and the Multi Variant Analysis (4-Way-ANOVA).

\section{Findings and Discussion of the study:}

The findings of the study are discussed through the answers of the participants and through the recommendations of the study.

\section{The results related to the first question:}

What are the basic necessary educational competences for the physical education teachers from their perspective?

To answer this question, the mean scores and the standard deviations were done for each domain of the instrument accordingly from the highest mean score. This is shown in Table (3)

Table (3)

Mean scores and Standard Deviations for the Basic Educational Competences for the Physical Education Teacher According to the Domains of the Study Arranged According to the Mean Scores

\begin{tabular}{|c|l|c|c|c|}
\hline No. & \multicolumn{1}{|c|}{ Domain } & $\begin{array}{c}\text { Mean } \\
\text { Score }\end{array}$ & $\begin{array}{c}\text { St. } \\
\text { deviation }\end{array}$ & $\begin{array}{c}\text { Degree of } \\
\text { importance }\end{array}$ \\
\hline 1. & Planning & 3.62 & 0.88 & high \\
\hline 2. & Carrying out the educational situation & 3.60 & 1.03 & high \\
\hline 3. & Management of the educational Situation & 3.58 & 1.08 & high \\
\hline 4. & Assessment & 3.51 & 1.46 & high \\
\hline & & 3.52 & 1.03 & high \\
\hline
\end{tabular}

The results in Table (3) showed that all the educational competences were important having a high degree for the physical education teachers. The total mean score was (3.52). This could be explained if the teachers consider such competences very important for the physical education teachers in order to be able to accomplish their job successfully because physical education is a basic ground for the students that enables them to gain important physical skills to be in good shape. As a result, this will be reflected on their personalities mentally, emotionally socially and healthy. This result was in harmony with what Shetewi (2001) , Fakhuri and Bin Ali (2002), Abu Nemrah (2003), Abdel Haq and Saleh (2004) and AL Omari (2005) have achieved in their results, The results of such studies indicated that male and female teachers think that the teachers should have the necessary educational 
competences in teaching, It is clear from the findings in Table (3) that planning domain got the first rank among the domains of the study; whereas the practice degree was high which is educationally accepted. Planning competency is considered the first step in the process of effective teaching, because it helps teachers to identify the skills the students should acquire. In addition, planning helps in forming the objectives behaviorally and measurably in addition to the choice of teaching methods and assessment. Planning is the cornerstone in the educational process which let the teachers carry out their lessons properly. This finding of the study in this domain did not get along with the study of, AL Ja'neeni (2000) and Kilber (2002) where planning in such studies came in the third rank. The least practice domain was assessment in a high degree which might be attributed to the lack of time for physical education teachers because of their heavy duties, such as daily preparation and activity planning that their schools share inside the school and outside. This could be a burden in addition to less practical training for some in-service teachers in measurement and evaluation.

Educational situation management competency came in the second rank in a high practice degree attributed to the physical education teachers' belief of the importance of this competency in the teachers' success in achieving the educational objectives depends on the competency of management. Because not being able of managing the class causing chaos inside the classroom which makes carrying out the educational activity process very difficult.

In the third rank, there was the educational carrying out situation competency in high practice degree attributed _ as the researchers think to the solid and effective ground role of this competency which is greatly followed up by the principals and the educational supervisors in attending some classes for the teachers. In addition the parents follow up for physical education classes to check educational experience skills for their children.

\section{The Second Question:}

Are there any differences in the physical education teachers' perspective in the Governorate of Ajloun in their estimation for the basic necessary educational competences for teaching the physical education due to the variables: sex (male ,female), the educational stage ( secondary, basic , secondary and basic together) academic level (B,A, degree, after $\mathrm{B}, \mathrm{A}$, degree) experience years (5 years ,6-10-, over 11 years) ?

To answer this question the mean scores and standard deviations for the teachers' estimation for the educational competences for teaching the physical education attributed to sex, educational stage, academic level and experience years were done. Table (4) explains that.

Table (4)

Mean Scores and Standard Deviations for the Teachers' Estimation for the Basic Necessary Educational Competences for Teaching Physical Education

\begin{tabular}{|c|c|c|c|c|}
\hline \multicolumn{2}{|c|}{ Variable } & No, & Means & St. deviation \\
\hline \multirow{2}{*}{ Sex } & Male & 34 & 2.70 & 0.81 \\
\hline & Female & 45 & 2.80 & 0.75 \\
\hline \multirow{2}{*}{ Academic level } & B.A. & 60 & 2.71 & 0.83 \\
\hline & After B.A & 19 & 2.79 & 0.72 \\
\hline \multirow{3}{*}{$\begin{array}{c}\text { Educational } \\
\text { Stage }\end{array}$} & Secondary & 10 & 2.68 & 0.84 \\
\hline & Basic & 26 & 2.90 & 0.77 \\
\hline & $\begin{array}{c}\text { Secondary and } \\
\text { Basic }\end{array}$ & 43 & 2.82 & 0.90 \\
\hline \multirow{3}{*}{$\begin{array}{c}\text { Experience } \\
\text { years }\end{array}$} & 5 years & 27 & 2.73 & 0.87 \\
\hline & $6-10$ years & 16 & 2.60 & 0.86 \\
\hline & Over 11 years & 36 & 2.70 & 0.89 \\
\hline
\end{tabular}

It is clear from Table (4) that the mean scores for all variables were close to each other. In order to reveal the differences between the previous mean scores for the teachers' 
estimation for the basic necessary educational competences for teaching physical education attributed to sex, educational stage, academic level and experience years, Multi-Variable Analysis, 4-Way ANOVA was done. This is explained in Table (5).

Table 5

Results of 4-Way ANOVA to Reveal the Differences Among the Mean Scores and Standard Deviations for the Teachers' Estimation for the Basic Educational Competences in Teaching Physical Education Attributed to Sex, Social Status, Academic level, Experience years.

\begin{tabular}{|c|c|c|c|c|c|}
\hline $\begin{array}{c}\text { Source of } \\
\text { variance }\end{array}$ & Total & $\begin{array}{c}\text { Freedom } \\
\text { degree }\end{array}$ & $\begin{array}{c}\text { Means of } \\
\text { squares }\end{array}$ & F-value & $\begin{array}{c}\text { Degree of } \\
\text { reference }\end{array}$ \\
\hline Sex & 0.43 & 1 & 0.23 & 0.31 & 0.77 \\
\hline Social status & 0.23 & 1 & 0.13 & 0.17 & 0.88 \\
\hline $\begin{array}{c}\text { Academic } \\
\text { level }\end{array}$ & 1.42 & 2 & 0.73 & 0.98 & 0.39 \\
\hline $\begin{array}{c}\text { Experience } \\
\text { years }\end{array}$ & 0.15 & 2 & 0.52 & 0.06 & 0.95 \\
\hline $\begin{array}{c}\text { Error } \\
\text { percentage }\end{array}$ & 83.17 & 77 & 0.70 & & \\
\hline Total & 90.03 & 78 & & & \\
\hline
\end{tabular}

It is clear from Table (5) that there were no statistically significant differences at the level $(\alpha$ $=0.05)$ among the mean scores for the teachers' estimation for the basic necessary educational competencies for teaching physical education for the participants attributed to the variables : sex , social status, academic level and experience years. The researchers think this result is due to all physical education teachers who believe that the process of teaching is based on those competences whatever the subjects they are teaching. In addition, such competences might change the negative attitude towards the importance of playing education lessons by not considering such lessons as additive lessons and could not be taught by any teacher and the physical education class is just for playing doesn't need competences as other subjects-as it was thought. However, such competences for physical education are followed up by the principals and the educational supervisors. In addition, the academic level of physical education is nearly the same in the Governorate of Ajloun. All those teachers hold B.A. degree in physical education and have the same in-service training, as well as they all have the same conditions of being followed up by educational supervisors and principals. Therefore, all those physical education teachers, regardless their sex, social status, academic level or experience years have agreed upon the importance of having the educational competences. The findings of this study is in harmony with the findings of the studies of, AL Ja'neeni (2000), Fakhuri and Bin Ali (2002) and Abu Nemrah (2003).All those studies indicated no statistically significant differences in the importance degree of the availability of educational competences for the teachers included in the sample of those studies due to the variable of sex. Meanwhile, this study did not get along with the findings of the studies of AL Oleimat and AL Qutaish (2007) which showed statistically significant differences in favor of the female teachers in the science teacher practice for the educational competences of planning and assessment. The findings of this study was also in agreement with the findings of Al Hammadi, AL Ja'neeni (2000) Fakhuri and bin Ali (2002), Abu Nemrah (2003), The findings of those studies indicated statistically significant differences in the educational and teaching competences due to the variable of academic level. The finings of this study was in disagreement with the findings of Shetewi (2001) and AL Omari (2005). The findings of those studies showed statistically significant differences in the educational and teaching competences due to the academic level in favor of the highest. The findings of this study also got along with the findings of Fakhuri and AL Ben Ali (2002), Abu Nemrah (2003), and AL Oleimat and Qutaish (2007). The findings of those studies indicated no statistically significant differences in the educational and teaching competences due to experience years. The findings of this study also disagreed with the findings of AL Ja'neeni (2000) and AL Ben 
Ali and Murad (2003). The findings of those studies indicated statistically significant differences in the educational and teaching competences due to the experience in favor of female teachers who have longer experience.

\section{Conclusions:}

The study came up with the following findings:

1. The importance of all educational competences included in the instrument of the study for the physical education teachers. The arrangement according to the importance was: carrying out the classroom situation, managing the educational situation, playing and assessment.

2. There were no differences between the physical education teachers for the importance of the educational competences according to the variables: sex, academic level, teaching experience and the educational stage.

\section{Recommendations:}

In light of the objectives and findings of the study, the researchers have come up with the following recommendations:

1. Using the list of educational competences of the findings of this study in the educational supervision for following up and assessing the performance of the physical education teachers and benefiting from such competences in preparing training programs for the in - service teachers.

2. Organizing training courses for the physical education teachers to develop their educational competences that meet their needs while following up their performance.

3. Working on developing the teachers' skills and competences in having and practicing a group of teaching competences related to using self-assessment methods for students through training courses .

4. Conducting other more studies depending on direct observation for the teachers while carrying out their physical education lessons to be certain of the availability of the performance competences and their practice for such competences.

\section{References:}

1. Abdel Haq, Emad Saleh (2004). Basic Educational Competences for Physical Education Teachers for Basic stage in Naples Governorate. Educational and Psychological Science Magazine V. ( 5 ), NO ,(4), pp 115_ 138.

2. Abu Nemrah, Mohammad Khamees Hussein (2003). The Basic Educational performance competences for ht Basic stage Teachers for teaching the physical Education. AL Najah university Magazine for Research (Human science) V,1. (17), NO, (2).

3. AL Bin Ali. Adnanah Sa'eed AL Megbel and Murad, Sameer Yousef (2003). The Teaching competences for Social Subjects Teachers in the Preparatory Stage in Qatar as Being Reflected by the classroom Assessment, Educational Science Magazine, No. (3) Janycary , Qatar , PP.143-172.

4. AL Helah, Mohammad (2002) Classroom teaching skills. Amman: Dar AL-Maseerah.

5. ALghezwat, Mohammad Ibraheem (2002). Available Educational Competences for Student Teachers, History and Geography Teachers Domain specialization in Mu'tah University from the Perspective the Teachers in Kerak Governorate Schools: Jordan. Um al Qura University Magazine for Education, Social and Human Science, V,1. (14), No (1), PP 1230 .

6.AL - Fatlawi, Suhaila (2003). Teaching competences, Amman: Dar AL Shroug for Publication and Delivering.

7. AL Oleimat, Ali Megbel and AL Qutaish, Hussein Mushaweh (2007).The Degree of Performance practice for Educational Science Educational Performance Competences in the Basic stage schools in the Governorate of Mafraq. Um AL Qurah University Magazine for Human and Educational science. V,1. (19), NO (2) ,pp. 152_202.

8. AL Omari, Mohammad Abdel Qader (2005). Necessary Educational Competences for Computer teachers in the secondary stage and their Practice Degree from the Teachers, perspective. Mu'tah for Research and Studies. Vl, (20), N0 (7), pp 85 _ 115. 
9. AL Muzaien, Sulaiman Hussin. And Ghurab, Hisham Ahmad (2005) Basic Competences for Kindergarten Nanies from the Perspectives of the Principals. A Research presented to the second educational Conference (Palestinian Child between Challenging the Reality and Future Ambition). Held in the Faculty of Education in the Islamic University in (2223/11/2005) Gaza.

10. AL Nashef, Huda Mahmoud (2003). Kindergartens Teacher. Ed.(1) Amman : Dar AL Fikr AL Arabi.?

11. AL Subai'i , Huda Turki (2003) . Studying Teaching Competences in its Relation with Personal Characteristic for Research Studies Teachers. Educational ResearchCenter Magazine. No.( 23) . p. 66.

12. Fakhuri Ayshah Ahmad and AL Ben Ali, Hasha, Hasan (2002). Educational competences for 5th and 6th teachers in the primary stage in Qatar. Majalat Risalt Al Tarbiah and psychology , (14) Qatar.

13. Jamel, AbdelRahman (2001). Educational competences in Measurement and Evaluation and its Acquisitions by Self- Learning. ed. (2) Amman: Dar AL Manahej for publications and Delivering.
14. Ja'neeni, Na'eem Habeeb (2000). Basic Competences for Teachers in Secondary Education in Jordan from their own Perspective. Social Education studies Magazines Vl , (27), NO. (1), University of Jordan: Amman .PP. 5774.

15. Gary.k.H(1980)college teaching to day: A Hand book for post-secondary Instruction.Boston,allyn\&Bacon.Inc

16. Kilber,H.E(2002).educational competences among history teachers in Nevada puplic school, the educational research journal NO $(1,13,145$ 155)

17. Mare'i, Tawfeeq Ahmad(1983). Educational comptrnces in ilght of sestems ed(1), Dar Alfurqan : Amman .

18. Mare'i, Tawfeeq and Balqees, Ahmad (1986) .Morals of Teaseling Career. Sultonate of Oman: Muscat, Ministry of education.

19. Shetewi, Mu'amar Hosni (2001) .The Extent of practice for the Necessary competences for Biology teachers in teaching Biology in the North of Palestine, Un published M, A. Degree, AL Najah National university. Naplus. 